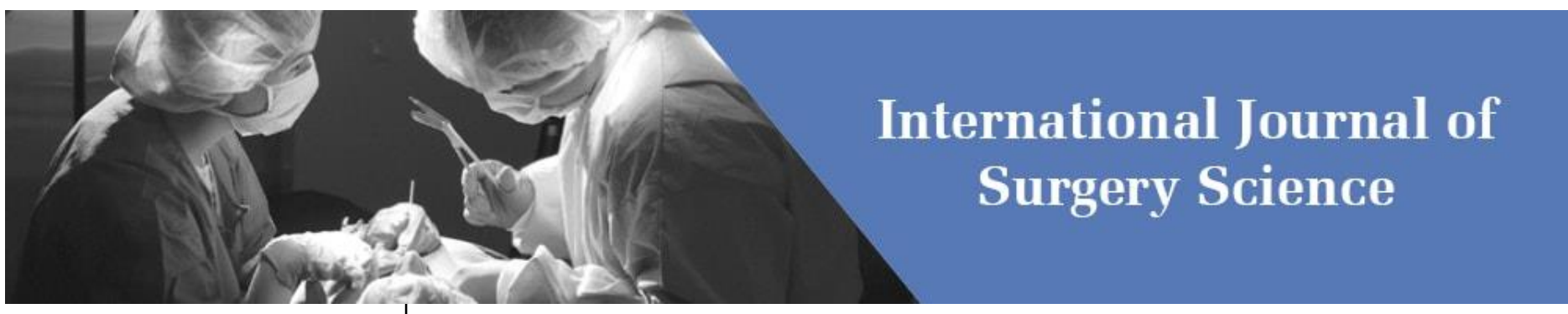

E-ISSN: 2616-3470

P-ISSN: 2616-3462

(C) Surgery Science

www.surgeryscience.com

2021; 5(2): 96-97

Received: 25-02-2021

Accepted: 27-03-2021

\section{Dr. Santhi}

Professor, Department of General Surgery, Government Royapettah

Hospital Affiliated with

Government Kilpauk Medical

College \& Hospital - Chennai,

Tamil Nadu, India

\section{Dr. Maheshwa}

Department of General Surgery, Government Royapettah Hospital Affiliated with Government Kilpauk Medical College \& Hospital - Chennai, Tamil Nadu, India

\section{Dr. Shanmugam}

Department of General Surgery,

Government Royapettah Hospital Affiliated with Government

Kilpauk Medical College \&

Hospital - Chennai, Tamil Nadu, India
Corresponding Author:

\section{Dr. Santhi}

Professor, Department of General

Surgery, Government Royapettah Hospital Affiliated with

Government Kilpauk Medical

College \& Hospital - Chennai,

Tamil Nadu, India

\section{Dealayed presentation of flail chest with pneumothorax and paradoxical respiration in a trauma patient: Case report}

\section{Dr. Santhi, Dr. Maheshwar and Dr. Shanmugam}

DOI: https://doi.org/10.33545/surgery.2021.v5.i2b.669

\section{Abstract}

We report a case of 48 years male who presented with Chest Injury in Emergency causality Department. Chest X-ray showed fracture 2 nd to 5 th rib on right side. Treated conservatively. 2 days later he developed paradoxical Respiration with breathing difficulty. Chest $\mathrm{x}$-ray taken showed Right Side Pheumothorax. Right side intercostal Tube drainage done under local anaesthesia.

Keywords: flail chest, pneumothorax, paradoxical respiration, parenchymal and pleural injury

\section{Introduction}

Flail Chest with paradoxical Respiration is a rare presentation in trauma cases. Delayed presentation with breathing difficulty is also rare condition. Immediate identification and management of Pneumothorax in flail chest is an important life saving procedure in emergency Surgery.

\section{Case presentation}

A 48 years male admitted with complaints of Road Traffic Accident with Right side Chest wall injury in Emergency Department. Chest x-ray showed facture of right 2nd to 5th ribs anteriorly and laterally. CT-Chest showed the same findings with minimal Lung Parenchymal and Pleural Injury during first presentation. Two days later patient developed breathing difficulty and paradoxical respiration with decreased oxygen saturation. CT-Chest and Emergency chest x-ray taken, showed flail chest with Right side Pneumothorax. Planned for right side intercostals tube drainage. Incision made over the right side 5th intercostals space under local anaesthesia with monitored Anaesthesia care. Right side ICD done. Tube position \& functioning confirmed clinically and radiologically. Patient saved from breathlessness. Flail Chest treated by conservatively with padding. Post operatively Chest x-ray taken and Cardiothoracic opinion obtained. ICD removed on 4th post operative day and patient discharged.

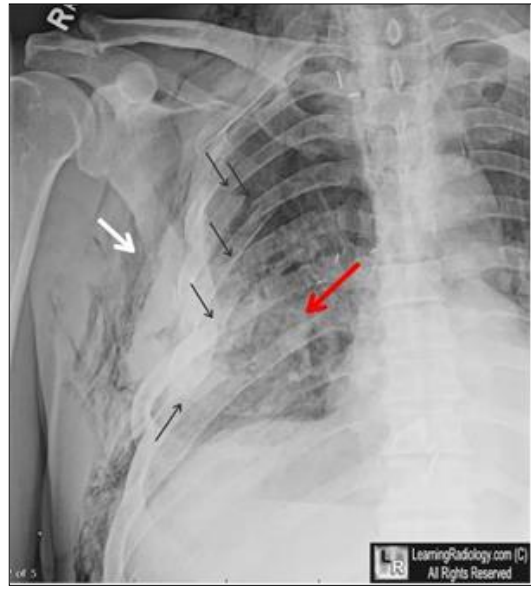

48 years Male - with multiple rib Fracture (Right Side)

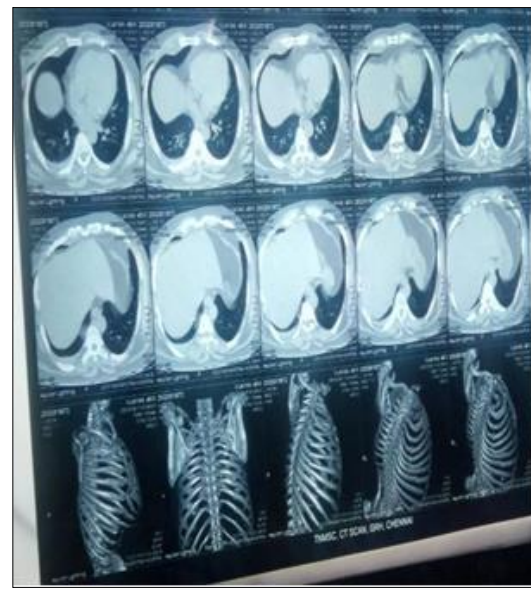

multiple rib Fracture with Flail Segments (Right Side) 

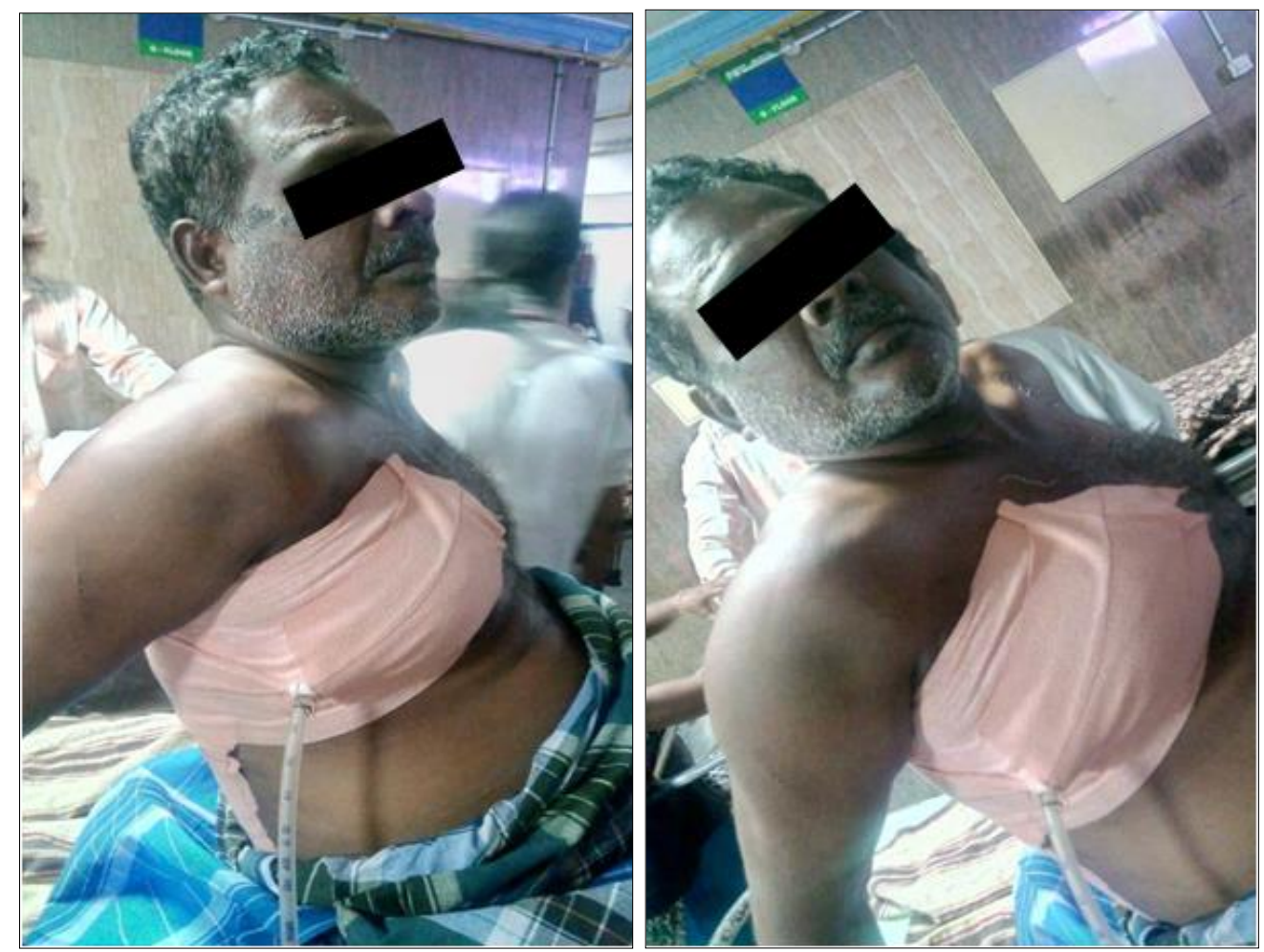

Post operative picture - Right side ICD Insertion

\section{Discussion}

Fracture of two or more consecutive ribs with each rib having two or more fracture sites such segments called as flail segment. Flail segments moves independent of adjacent thoracic cage. During inspiration flail segment moves inwards and during expiration the segment move outwards causing paradoxical respiration.

This paradoxical respiration causes reduction in ventilator lung surface and so respiratory dysfunction. All these derangements gets aggravated by pneumothorax and associated injuries. There is hypoventilation, carbondioxide retension and respiratory failure. Assisted ventilation is required for several days until chest wall stabilises. If ventilatory support is required for more than 10 days, then tracheostomy is done to prevent laryngeal stenosis which can occur due to prolonged endotracheal intubation.

\section{Conclusion}

In our case breathlessness and paradoxical respiration is due to delayed presentation of flail chest caused by rib fractures and treated effectively in appropriate time, with available Radiological Investigations and immediate intercostal Tube drainage.

\section{References}

1. Bastos R. Calhoon JH: Flail Chest and Pulmonary Contusion Semin Cardio thoracic Surgery 2008, 20(1).

2. Jayle CP, Allain G. Flail Chest in Polytrauma patients.

3. Nirula R. Allen-B-rib fracture stabilisation in patients sustaining blunt Chest Injury. 